\title{
Intramammary Syringe
}

National Cancer Institute

\section{Source}

National Cancer Institute. Intramammary Syringe. NCI Thesaurus. Code C149609.

Device for introducing a pharmaceutical form through the teat canal. 